\title{
TERRAS ALTAS DA MANTIQUEIRA UM PÓLO DE ECOTURISMO QUASE VIRTUAL
}

Joana Marins de Andrade Coutinho

Orientador: Sérgio Salazar Salvati

Monografia apresentada ao Centro de Excelência em Turismo da Universidade de Brasília como requisito parcial para obtenção do certificado de Especialista em Ecoturismo.

Brasília, DF, maio 2003. 


\section{TERRAS ALTAS DA MANTIQUEIRA UM PÓLO DE ECOTURISMO QUASE VIRTUAL}

Joana Marins de Andrade Coutinho

Banca Examinadora

Orientador

Membro da Banca

Brasília, DF, 26 de maio de 2003. 
Coutinho, Joana Marins de Andrade

Terras Altas da Mantiqueira: um pólo de ecoturismo quase virtual / Coutinho, Joana Marins de Andrade

$42 \mathrm{f}$.

Monografia (especialização em Ecoturismo) - Universidade de Brasília. Centro de Excelência em Turismo, Brasília, 2003.

Área de concentração: Turismo.

Orientador: Sérgio Salazar Salvati

1. Ecoturismo 2. Projeto Pólos de Ecoturismo 3. Terras Altas da Mantiqueira 
"Tudo vale a pena se a alma não é pequena".

Fernando Pessoa 
À minha família que sempre esteve comigo, mesmo longe. 
Agradeço a Lucila Egydio pela disponibilidade e paciência, a Sandra que me cedeu grande parte do material para pesquisa, aos meus amigos de Brasília, minha mãe e irmãos, pela preocupação e principalmente ao Paulo pela força, amizade, companheirismo e paciência. 


\section{RESUMO}

O ecoturismo é uma das atividades do turismo que mais cresce nos dias de hoje, além da preservação ambiental, estimula o envolvimento local e valoriza a cultura. O tema de estudo deste trabalho é: o pólo de ecoturismo Terras Altas da Mantiqueira situado no sul de Minas Gerais. O objetivo é mostrar que apesar de haver uma grande propaganda sobre este destino, algumas localidades não foram preparadas para receber o turista. Através de pesquisa em gabinete, sites da internet, entrevistas com alguns atores e visitas ao local foi analisada esta situação. A população e alguns empreendedores se sentem aquém deste circuito e ainda não podem colher frutos deste novo destino. A Associação das Terras Altas tenta hoje resgatar a confiança da população para que sejam inseridos de fato neste contexto. Sem planejamento não há desenvolvimento ordenado do turismo. 


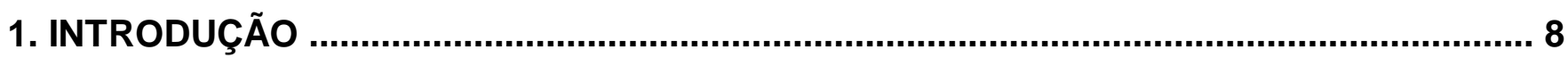

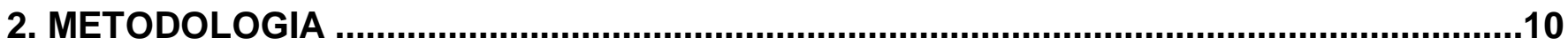

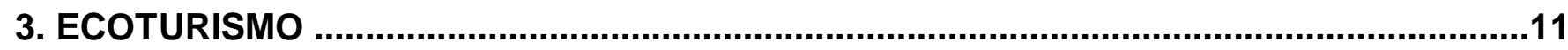

4. O PROJETO PÓLOS DE ECOTURISMO NO BRASIL …....................................................14

4.1 - Comitê Gestor do Programa Pólo de Ecoturismo ..............................................15

4. 2 - O que é um Pólo Ecoturístico? .......................................................................15

5. O DESENVOLVIMENTO DO TURISMO DE MINAS GERAIS...........................................17

6. MG4 - TERRAS ALTAS DA MANTIQUEIRA: UNIDADES FORMADORAS ...................... 19

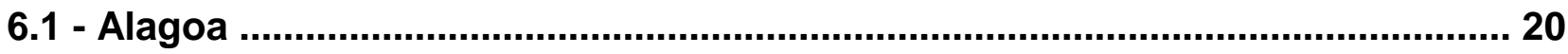

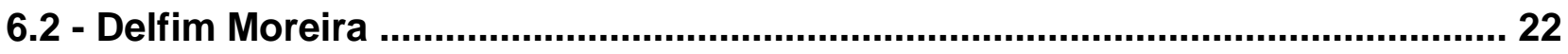

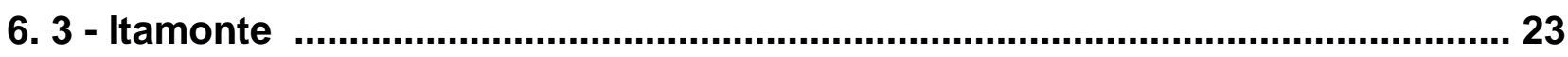

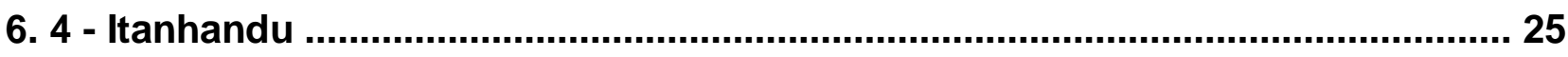

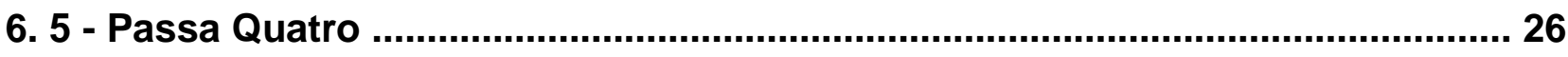

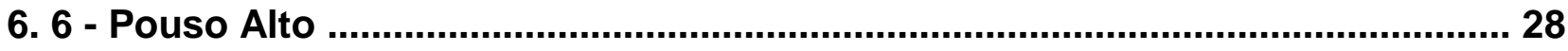

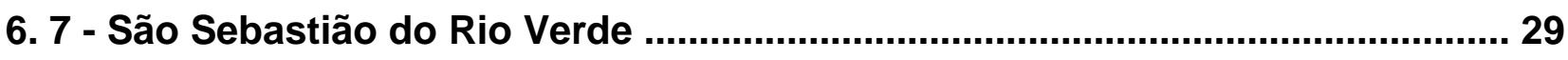

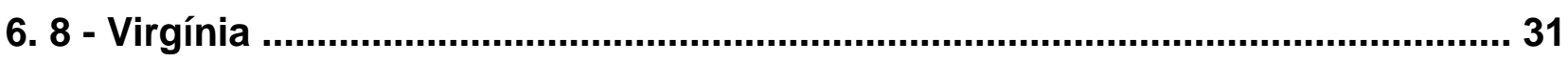

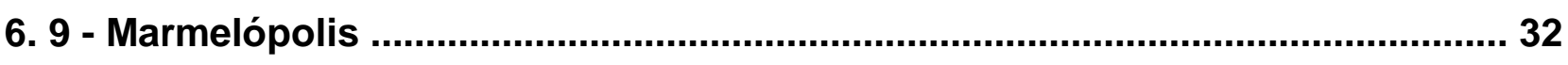

7. UM PÓLO DE ECOTURISMO QUASE VIRTUAL ......................................................... 34

8. CONCLUSÃO

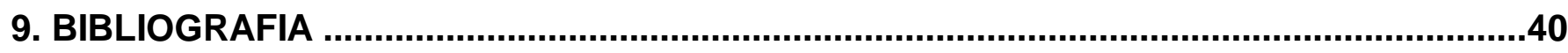

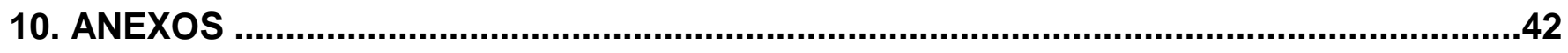




\section{INTRODUÇÃO}

O turismo é uma das atividades sócio-econômicas que mais cresce nos dias de hoje. Além de gerar empregos, divisas para a região e o país, crescimento, gera também, melhorias na infra-estrutura local e trás benefícios para a população envolvida. Uma das modalidades do Turismo que mais cresce hoje em nosso país e em todo o mundo é o ecoturismo. Além de utilizar o meio ambiente como atrativo principal, valorizando a natureza e aspectos culturais, é necessário que a comunidade esteja dentro do processo.

Através de estudos de gabinetes e alguns levantamentos com pessoas envolvidas no projeto Pólos de Ecoturismo, foi feita uma análise da situação atual de um desses pólos: "Terras Altas da Mantiqueira" que envolve hoje 09 municípios do Sul de Minas Gerais. Este programa criado pela Embratur juntamente com outras parcerias visa desenvolver o Ecoturismo em regiões que, de alguma forma já desenvolvem estas atividades. Através de estudos prévios de cada região do país foram identificados 96 Pólos em todos os estados brasileiros. Um projeto pioneiro no estado de São Paulo, no Pólo Lagamar deu início e a este trabalho tão importante do governo brasileiro.

Através de atividades planejadas o ecoturismo pode ser desenvolvido de forma sustentável, ou seja, o meio ambiente vai ser utilizado de uma forma em que as gerações futuras também possam usufruir deste bem tão valiosos que possuímos hoje. A conscientização ambiental das populações envolvidas e dos próprios visitantes também é um dos objetivos deste programa. Na verdade este programa veio para "dar uma luz" as cidades ou comunidades que desenvolviam o ecoturismo, mas não sabiam como otimizar os serviços, conquistar os clientes, melhorar o atendimento, formatar um produto, e até conservar o meio ambiente.

Terras Altas da Mantiqueira é um Pólo com um potencial muito grande, mas sem vontade política e envolvimento real das comunidades envolvidas não vai ser implementado de fato. De forma desordenada, o desenvolvimento do 
Ecoturismo pode trazer danos para o meio ambiente, ou seja, os municípios podem estar desperdiçando um grande potencial.

O objetivo deste trabalho é, portanto analisar o Pólo: "Terras Altas da Mantiqueira". Mostrar o potencial existente em cada cidade participante deste pólo, que hoje se tornou um circuito mineiro. Mostrar como uma campanha de marketing e um jogo de interesses políticos podem fazer com que uma região se torne um destino turístico sem na verdade, ter sequer infra-estrutura para receber turistas.

O Ecoturismo, apesar de não estar consolidado na maioria das localidades que o desenvolvem pode ser a grande solução para os problemas ambientais existentes nos dias de hoje. A população só preserva aquilo que conhece. Além de utilizar o meio ambiente, a cultura também é resgatada e valorizada pela população e turistas que compram este produto. Aumentar a auto-estima e a consciência ambiental são grandes desafios do ecoturismo também. 


\section{METODOLOGIA}

A metodologia proposta para analisar a situação definida foi:

1) Levantamento de dados em sites oficiais de turismo do governo de Minas Gerais para se conhecer mais as cidades integrantes deste circuito. O site de busca utilizado foi o google (http://www.google.com.br) e foram usadas palavras chaves como: Terras Altas da Mantiqueira, circuitos mineiros, secretaria de turismo de Minas Gerais entre outras.

2) Pesquisa em gabinete em manuais e livros sobre 0 assunto, como consta na bibliografia. Através da ATAM (associação das Terras Altas da Mantiqueira) foi possível adquirir o Plano de desenvolvimento turístico das Terras Altas da Mantiqueira realizado pela "PLANO \& MENSAGEM" uma empresa de São Paulo contratada para realizar o mesmo. Também foi possível conseguir o Estatuto Consolidado da Sociedade Civil denominada Terras Altas da Mantiqueira (anexo 1) e algumas atas de reuniões realizadas por esta Associação.

3) Entrevista com o secretário de turismo de Delfim Moreira, sr Marcelo Braga (anexo2). Entrevista com o proprietário da Pousada Solar da Mantiqueira e Restaurante Canto do Caipira (anexo3) Sr. Eduardo.

4) Visitas à região das Terras Altas da Mantiqueira.

5) Análise dos dados coletados. 


\section{ECOTURISMO}

As raízes do ecoturismo encontram-se na natureza e no turismo ao ar livre. De acordo com Kreg, 1999 os milhares de visitantes de parques nacionais, os aventureiros que escalaram o Himalaia ou desbravaram selvas a procura de aventura, foram tão ecoturistas quanto os milhares que hoje fotografam pingüins na Antártida, acompanham migração de pássaros no Pantanal ou dormem nas habitações comunitárias dos nativos de Bornéu.

O século $X X$ assistiu a uma mudança drástica nas viagens a áreas naturais. Turistas que saiam de seu país para fazer safáris de caça na África, hoje continuam saindo de seus países, não para matar grandes mamíferos, mas para fotografá-los. A consciência ecológica e preservacionista estão cada vez mais presentes nestes grupos de turistas e da própria população que os recebe. A população sabe que ganhará mais se puder levar cada vez mais turistas para conhecer estes grandes animais do que levar apenas um grupo e acabar com este atrativo.

O ecoturismo é mais que uma pequena elite de amantes da natureza. É na verdade, uma maneira de assegurar a conservação da natureza e aumentar o valor das terras deixadas em estado natural. Os lucros gerados por esta atividade devem reverter para assegurar a conservação ambiental, garantir o seu sucesso como empreendimento econômico e proporcionar reais benefícios às populações residentes no local ou entorno das atividades.

Ecoturismo, em outras palavras envolve tanto um sério compromisso com a natureza como responsabilidade social. Essa responsabilidade deve ser assumida também pelo viajante, ou ecoturista. Utilizar os recursos naturais e culturais de forma sustentável, oferecer produtos de elevada qualidade aos visitantes, contribuir para a distribuição justa dos benefícios econômicos gerados, possibilitar o desenvolvimento de empreendimentos criados e gerenciados pelas próprias comunidades, preparar ao ambientes para a experiência da visitação e não transformá-los a fim de atender as expectativas 
dos visitantes, são alguns "mandamentos" do ecoturismo. Isso significa uma completa mudança de mentalidade. Afinal é necessário atender bem o público, que é diferente do turista convencional.

O interesse crescente pelo ecoturismo entre os governos dos países em desenvolvimento, os operadores comerciais, as organizações assistenciais e os conservacionistas dão a dimensão de seu enorme potencial econômico e conservacional. Os ecoturistas gastam bilhões de dólares todos os anos a procura deste retorno à natureza, utilizando recursos e mão de obra local. Isso se traduz em entrada de divisas do exterior, projetos adequados ao meio ambiente e engajamento dos moradores da região na indústria de viagens.

Como toda atividade humana, o ecoturismo oferece grandes possibilidades de desenvolvimento, mas também envolve riscos, nas áreas: ambiental, econômica e sociocultural da atividade. Quando bem planejado e monitorado, gera diversos aspectos positivos e quando isso não acontece o contrário se torna verdade e impactos negativos acontecem. Nos aspectos ambientais podemos notar que ao mesmo tempo em que gera o estímulo aos estudos de fauna e flora, implantação de infra-estrutura básica, saúde, comunicação, segurança, educação, desenvolvimento e conservação da natureza, gera poluição do ar, água, solo, sonora e visual, compactação e erosão do solo, mudanças numéricas em populações silvestres e etc (Ferreira, 2002). Estes são alguns pontos que podemos comparar uma ação positiva e negativa desta atividade quando não planejada corretamente.

Esta atividade vem sendo discutida em nosso país desde 1985, mais conhecida na época como turismo de natureza ou ecológico, praticada por pequenos grupos e de forma pouco ordenada. Em 1987 ocorreu a primeira iniciativa governamental de proceder a uma proposta de ordenação, com a criação da Comissão Técnica Nacional da qual faziam parte, representantes do Instituto Brasileiro do Meio Ambiente e dos Recursos Naturais Renováveis IBAMA e do Instituto Brasileiro do Turismo - EMBRATUR e cujo objetivo era implantar e monitorar o Projeto de Turismo Ecológico. Somente em agosto de 
1994, o Grupo de Trabalho Interministerial em Ecoturismo, que reuniu o Ministério da Indústria, Comércio e Turismo e o Ministério do Meio Ambiente e da Amazônia legal, além da Embratur, Ibama, empresários e consultores, chegou a seguinte conceituação para Ecoturismo:

"Um segmento da atividade turística que utiliza, de forma sustentável, o patrimônio natural e cultural, incentiva sua conservação e busca a formação de uma consciência ambientalista através da interpretação do ambiente, promovendo o bem-estar das populações envolvidas" (Diretrizes para uma Política Nacional de Ecoturismo, MIC/MMA, 1994).

Este documento foi chamado de "Diretrizes para a Política Nacional de Ecoturismo" e passou a nortear grandes trabalhos desenvolvidos na área. A valorização e o reconhecimento do potencial e importância do ecoturismo começavam a aparecer em ações governamentais e na iniciativa privada. $\mathrm{O}$ conceito de ecoturismo utilizado ao longo deste trabalho será: o adotado pela Embratur descrito através da Política Nacional de Ecoturismo. Dentro desta política destacam-se alguns objetivos como: a preservação do meio ambiente, com o desenvolvimento sustentado, melhoria da qualidade de vida e desenvolvimento regional, a geração de divisas e empregos, a formação de mão de obra e de um produto turístico competitivo, inclusive com a inserção internacional e a satisfação do cliente.

Para efeito deste estudo, foi feita uma análise de dados sobre o Programa Pólos citado anteriormente e mais precisamente o estudo deste trabalho o Pólo: Terras Altas da Mantiqueira, que hoje em dia, na verdade, tornou-se um circuito dentro de muitos outros desenvolvidos pelo governo de Minas Gerais juntamente com as cidades e populações envolvidas. O principal objetivo destes pólos é o desenvolvimento do ecoturismo e conseqüentemente da região onde ele está inserido. Melhorias podem ser feitas se está atividade for realizada de forma participativa e ordenada. 


\section{O PROJETO: PÓLOS DE ECOTURISMO NO BRASIL}

Segundo Magalhães,2001. Em 1997 a Embratur, em conjunto com o Instituto de Ecoturismo do Brasil - IEB, iniciou o Projeto Pólos de Ecoturismo no Brasil. O programa abrange todo o território brasileiro, e já identificou 96 regiões ou pólos com potencial para o desenvolvimento de atividades ecoturísticas. Estes pólos estão distribuídos nos 26 estados brasileiros, em 550 municípios, envolvendo uma população de mais de 40 milhões de habitantes. O projeto foi desenvolvido em quatro etapas distintas:

a) Conceituação: desenhado o cenário de possíveis pólos em cada estado brasileiro.

b) Levantamento: Coleta de dados através de inventários e entrevistas com autoridades, membros do trade turístico e das comunidades através de registros fotográficos e coleta de material informativo. Visita ás secretarias estaduais de turismo de alguns estados para se levantar a postura e expectativas dos secretários e sua equipe quanto a consolidação de um pólo ecoturístico em cada local objeto de estudo.

c) Diagnóstico: Após o processamento dos dados levantados foi possível fazer uma análise da situação atual das localidades assim como fazer considerações sobre seu potencial de crescimento e desenvolvimento

d) Proposições: para que o projeto tenha continuidade é necessário que mecanismos de gestão se estabeleçam dentro do poder público Estadual, Municipal e também ações integradas com a iniciativa privada. Dentro destas proposições foram feitas algumas recomendações aos estados e municípios integrantes deste projeto.

I - Implementação de uma política de desenvolvimento sustentado que tenha o ecoturismo como ferramenta e modelo;

II - Instalação de Comitês para a gestão dessa política, em cada pólo; 
III - Enfrentamento dos principais desafios apontados pelos estudos de campo e diagnósticos, como: vias de acesso, orientação e oferta dos produtos turísticos e sinalização.

Este programa possui três objetivos principais:

1- Identificar as localidades brasileiras aonde a prática do ecoturismo já vem ocorrendo com algum sucesso e aquelas outras com potencial de desenvolvimento, mas ainda carentes de infra-estrutura e recursos humanos capacitados;

2- Fazer um levantamento das características, das potencialidades e das condições da infra-estrutura nos locais onde o ecoturismo se apresenta como uma nova alternativa de desenvolvimento e;

3- Propor metodologias de planejamento, projeto e gestão visando a implantação dos pólos ecoturísticos, segundo os princípios do desenvolvimento sustentável.

\section{1 - Comitê Gestor do Programa Pólo de Ecoturismo}

Para cada pólo, dentre as proposições apresentadas foi sugerida a constituição de um comitê composto por representantes dos municípios integrantes. A partir da estruturação, o comitê deverá propor uma agenda permanente de trabalho para difundir e ampliar a participação local, iniciar os procedimentos de estudos e pesquisas e até desenvolver campanhas promocionais.

\section{2 - O que é um Pólo Ecoturístico?}

Segundo o manual "Pólos de Ecoturismo: planejamento e gestão" são considerados pólos de ecoturismo "áreas aonde as atividades ecoturísticas já vêm sendo desenvolvidas com sucesso, sendo promovidas por um número 
variável de agentes, ou locais com condições naturais especiais, mas poucas atividades devido à falta de infra-estrutura e de organização".

Não basta que uma localidade tenha atrativos naturais e culturais para ser considerado um pólo ecoturístico. Este mesmo lugar tem que possuir infraestrutura básica e turística para atender não somente a população local, mas também aos turistas que chegarão a estes locais. Deve haver também vontade política para que estes projetos relacionados ao pólo saiam do papel para a real implantação deste projeto.

Foram identificados em todos os estados brasileiros várias regiões para desenvolvimento destes pólos de Ecoturismo. A região Sudeste, por possuir muitos atrativos naturais e culturais, além de uma infra-estrutura para o desenvolvimento da atividade de ecoturismo, foi contemplado com 26 pólos de ecoturismo, definidos pelos critérios do programa. Dentro da região Sudeste será analisado o estado de Minas Gerais, mais especificamente o pólo MG4 definido como "Terras Altas da Mantiqueira", um pólo que a princípio possuía 07 cidades e após algumas alterações hoje possui 09 cidades integrantes deste pólo.

A princípio Terras Altas da Mantiqueira seria trabalhado como pólo de ecoturismo. Após alguns estudos realizados pelo governo de Minas Gerais, foram criados vários circuitos de turismo para o Estado. A partir daí este pólo se tornou e vem sendo trabalhado como um circuito de turismo e não somente de ecoturismo. 


\section{DESENVOLVIMENTO DO TURISMO DE MINAS GERAIS}

De acordo com dados retirados do site da secretaria de turismo de Minas Gerais, o estado de Minas Gerais limita-se ao norte com a Bahia, a oeste com Goiás e Mato Grosso do Sul, ao sul com São Paulo e a leste com o Rio de Janeiro e Espírito Santo. O relevo é predominantemente montanhoso com áreas de menor altitude representada por depressões. O clima é variado nas diferentes altitudes.

O povoamento da região de Minas Gerais aumentou consideravelmente após a descoberta de ouro em Ouro Preto, no final do século XVII. No século anterior, no entanto, comerciantes já se deslocavam pelo estado em busca de madeiras e outros produtos vegetais. Com o ciclo do ouro ocorreu um rápido desenvolvimento econômico e a ocupação se fez de maneira muito intensa. É desta época o embrião de muitas cidades como a Vila Real de Sabará (atual Sabará), Vila Rica (Ouro Preto), Tiradentes, Ribeirão do Carmo (atual Mariana), entre outras.

Em menor grau, também o sul do estado deve sua ocupação à exploração de jazidas auríferas em localidades como Aiuruoca, Itajubá, Ouro Fino e Lavras. Por sua vez a ocupação do norte está relacionada à descoberta de diamante nas regiões de Diamantina e Serro.

O Ciclo do Ouro durou do final do século XVII até o fim do século XVIII; enriqueceu Minas Gerais tornando-a referência até mesmo para a metrópole que começou a impor restrições à sua atividade econômica, resultando na Inconfidência Mineira. Com o esgotamento das jazidas de ouro, a economia mineira entrou em decadência, só se revigorando no século XIX, com a atividade cafeeira. Atualmente o setor industrial, com um parque amplo e diversificado, responde por $26,3 \%$ da produção estadual, sendo que a mineração e a metalurgia estão entre as principais atividades do setor, ao lado da indústria automobilística. 
O turismo começou a ser estruturado com a criação da TURMINAS, em 1979 e depois com a BELOTUR que coordenou vários investimentos para dar apoio ao turismo de negócios, destacando-se o "Minas Centro" para feiras e congressos e os aeroportos da Pampulha e de Confins. No campo, os atrativos da vida rural favoreceram a criação de hotéis-fazenda e o início de programas de turismo rural. A existência de unidades de conservação como o Parque Nacional da Serra da Canastra, Parque Nacional de Itatiaia, Parque Nacional da Serra do Cipó, Parque Nacional da Serra do Caparaó e Parque Nacional Grande Sertão Veredas são muito importante para o desenvolvimento da atividade ecoturística, em suas várias modalidades.

O diagnóstico do turismo em Minas indicou-nos a necessidade de inovar o setor. Para alcançar este objetivo, a Secretaria de Estado do Turismo introduziu o conceito do circuito turístico. Através desta ação o turismo regional foi potencializado, pois, é a alavanca da atividade em todo o mundo. O circuito é um destino turístico que tem programas e projetos específicos de desenvolvimento. Congrega a participação da iniciativa privada, de organizações não-governamentais ligadas à atividade turística e ao poder público, cabendo a coordenação à iniciativa privada evitando, assim, o risco da descontinuidade.

O circuito turístico tem como vetor a sustentabilidade do desenvolvimento das ações propostas, não se submetendo à transitoriedade da representação político-institucional. Com muitas reservas florestais, rios, lagos e cachoeiras, serras e grutas, Minas Gerais é um grande destino para os amantes do ecoturismo. A estruturação dos pólos de ecoturismo nos circuitos oferece ao turista, a definição de roteiros interessantes e inteligentes, permitindo que o turista permaneça em Minas Gerais. 


\section{MG4 - TERRAS ALTAS DA MANTIQUEIRA: UNIDADES FORMADORAS}

Inicialmente foram identificadas 08 cidades para fazer parte deste circuito, que são: Alagoa, Itamonte, Itanhandu, Passa Quatro, Virgínia, São Sebastião do Rio Verde, Pouso Alto e São Lourenço. Depois de análise real do potencial de cada cidade esta estrutura foi readaptada. São Lourenço saiu do circuito Terras Altas, pois é uma cidade praticamente urbana, ou seja, não existe prática de ecoturismo, sendo um dos critérios fundamentais para fazer parte de um pólo de ecoturismo. São Lourenço é uma cidade que faz parte do Circuito das Águas de Minas Gerais. As cidades que entraram para este Pólo compondo as nove cidades foram: Marmelópolis, que possui uns dos maiores picos da região, o Pico dos Marins e muitas áreas para a prática do ecoturismo e Delfim Moreira, que possui paisagens belíssimas além de ter um atrativo cultural muito valioso.

De acordo com a secretaria de Turismo do Estado de Minas Gerais, o Circuito está situado entre sete picos, uns dos mais altos do País (Agulhas Negras), em meio à exuberância da floresta tropical da Mata Atlântica, com sua rica fauna, na região sul do Estado de Minas Gerais, bem perto dos três maiores centros urbanos brasileiros: São Paulo, Rio de Janeiro e Belo Horizonte. O local foi descoberto por bandeirantes em meados do século XVI, incluindo passagens de Martin Afonso de Souza e Fernão Dias Paes Leme, o Descobridor das Esmeraldas.

A região tem clima de frio, com temperaturas variando entre $5^{\circ} \mathrm{C}$ negativos e $27^{\circ} \mathrm{C}$. Nesse circuito estão os Parques Estadual do Papagaio e Nacional do Itatiaia, com espécies da Mata Atlântica e de Campos de Altitude. Muitas cachoeiras, corredeiras e rios permitem aos visitantes a pesca e a prática de várias modalidades de ecoturismo. A região é rica na produção de frutas tropicais, variedades de queijo e águas minerais. 

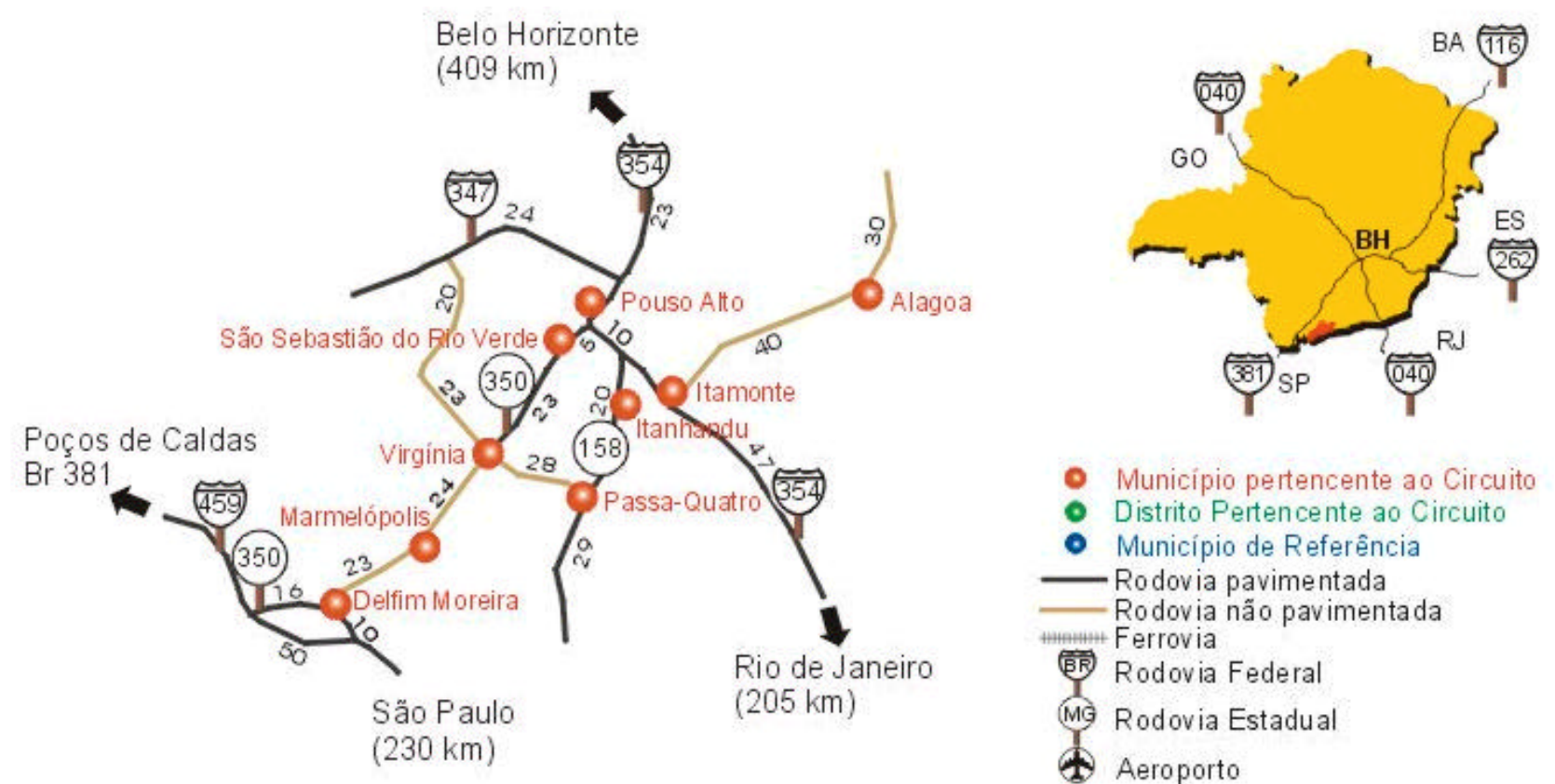

- Município pertencente ao Circuito

- Distrito Pertencente ao Circuito

- Município de Referência

Rodovia pavimentada

Rodovia não pavimentada

Ferrovia

(策) Rodovia Federal

(M) Rodovia Estadual

\$. Aeroporto

\section{1 - Alagoa}

A principal base econômica do município está na agropecuária e agroindústria. Queijo parmesão, prato e de minas são produtos exportados para o Rio de Janeiro e Vale do Paraíba. O carvão vegetal, produzido nas localidades de Condados e Bahia, é comercializado em Barra Mansa. A sede está a 1200 metros de altitude.

O antigo povoado formou-se, a partir de 1730, em torno da capela Nossa Senhora do Rosário da Alagoa da Aiuruoca, ligada à matriz de Aiuruoca. O local foi distrito dos municípios de Aiuruoca, de Itanhandu e, finalmente, de Itamonte, do qual se desmembrou para se emancipar em 1962. A região possui várias atrações naturais, dentre elas as cachoeiras do Zé Pena, do Zé Guedes 
e da Itaoca. Outra atração do local é o Garrafão, onde os jesuítas exploravam ouro. A área possui túneis escavados em pedras, riachos, área verde e é muito freqüentada como lugar místico.

Fonte: Secretaria da Cultura de Minas Gerais - 1999

\begin{tabular}{|l|c|}
\hline \multicolumn{2}{|c|}{ População Ocupada por Setores Econômicos } \\
\hline \multicolumn{2}{|c|}{$\mathbf{2 0 0 0}$} \\
\hline SETORES & №. DE PESSOAS \\
\hline Agropecuária, extração vegetal e pesca & 543 \\
\hline Industrial & 107 \\
\hline Comércio de Mercadorias & 103 \\
\hline Serviços & 289 \\
\hline TOTAL & $\mathbf{1 . 0 4 2}$ \\
\hline \multicolumn{2}{|c|}{ Fonte: Fundação Instituto de Geografia e Estatística - IBGE } \\
\hline
\end{tabular}

\section{Serviços}

Saúde:

1hospital(is) - 9 leito(s)

Fonte: SUS - Ministério da Saúde, 2001.

Hotéis: 2 Hotéis

Fonte: Associação Brasileira de Indústria de Hotéis - ABIH, 2000.

\section{Água e Esgoto}

Concessionária Água: Prefeitura Municipal

Concessionária Esgoto: Prefeitura Municipal

Fonte: Companhia de Saneamento de Minas Gerais, 2000. 


\section{2 - Delfim Moreira}

Como a maioria dos municípios da região, sua origem está ligada à chegada dos bandeirantes paulistas, em especial à bandeira de Borba Gato, que vinham à procura de ouro. $\mathrm{O}$ nome Descoberto dado a princípio ao lugar, passa a ser Descoberto de Itajubá, que significa pedra amarela, cachoeira, cascata e rio das pedras. Nos idos de 1746, a região de Itajubá, hoje Delfim Moreira, sofre modificações em suas divisas e passa a pertencer a Minas Gerais. Já em 1848, a freguesia é elevada a vila e, em 1938, a município.

A região é privilegiada e possui como atrativos turísticos o Clube de Campo Ninho da Águia, com cachoeiras, piscinas artificiais e naturais e áreas de lazer; o Mosteiro de Santa Maria de Serra Clara, dos monges beneditinos, em estilo europeu, com arcos, paisagem exuberante, pomares e jardins e, também, o Hotel Fazenda Pousado do Barão situado entre riachos e matas virgens, com rica fauna e cachoeiras.

A principal festa de Delfim Moreira é a da padroeira Nossa Senhora da Soledade, que tem início no dia 20 de dezembro e só termina em $1^{\circ}$ de janeiro. $\mathrm{Na}$ década de 60, a cidade viveu o 'boom' industrial na produção de doces, feitos com frutas da região. Foi a maior produtora de marmelo do Brasil, mas a quantidade produzida é menor hoje.

Fonte: Secretaria da Cultura de Minas Gerais - 1999

\begin{tabular}{|l|c|}
\hline \multicolumn{2}{|c|}{ População Ocupada por Setores Econômicos } \\
\hline \multicolumn{2}{|c|}{$\mathbf{2 0 0 0}$} \\
\hline SETORES & №. DE PESSOAS \\
\hline Agropecuária, extração vegetal e pesca & 1.240 \\
\hline Industrial & 400 \\
\hline Comércio de Mercadorias & 300 \\
\hline Serviços & 861 \\
\hline TOTAL & $\mathbf{2 . 8 0 1}$ \\
\hline \multicolumn{2}{|c|}{ Fonte: Fundação Instituto de Geografia e Estatística - IBGE } \\
\hline
\end{tabular}




\section{Serviços}

Hotéis: 1 Hotel

Fonte: Associação Brasileira de Indústria de Hotéis - ABIH, 2000.

\section{Água e Esgoto}

Concessionária Água: Prefeitura Municipal

Concessionária Esgoto: Prefeitura Municipal

Fonte: Companhia de Saneamento de Minas Gerais, 2002.

\section{3 - Itamonte}

Localizado no Sul de Minas. Com 428 quilômetros quadrados de área, numa das regiões de terras mais elevadas do Estado, vive da pecuária leiteira e da indústria de laticínios. A 906 metros de altitude, num clima de montanha, a cidade-sede se distancia de Belo Horizonte 442 quilômetros. Localizado em um dos pontos mais altos da serra da Mantiqueira, o povoado de Itamonte teve início no séc. XVIII com a crescente penetração das bandeiras paulistas nas terras de Minas. Por volta de 1818, com a região semipovoada, foi necessário construir um atalho que ligasse a capela do Capivari ao sopé do pico do Picu, para facilitar a comunicação com o Rio de Janeiro. Mais tarde foi erguida uma capela em homenagem a São José, ficando o povoado conhecido como São José do Picu. Já em 1927, passa a se chamar São José do Itamonte e, em 1938, simplesmente Itamonte, alcançando a condição de município.

A origem de sua denominação vem de um hibridismo tupi-português, com duas prováveis versões: pedra do monte ou montanha de pedra. Itamonte abrange uma porção do Parque Nacional de Itatiaia, além de constituir área de proteção da serra da Mantiqueira. Possui diversas cachoeiras e uma flora rica 
em araucária e jacarandá, o que a torna muito atraente aos adeptos do turismo ecológico. Também a festa de São José dia 19 de março, atrai visitantes à cidade, com apresentação de bandas locais e regionais, missas e shows.

Fonte: Secretaria da Cultura de Minas Gerais - 1999

\begin{tabular}{|l|c|}
\hline \multicolumn{2}{|c|}{ População Ocupada por Setores Econômicos } \\
\hline \multicolumn{2}{|c|}{$\mathbf{2 0 0 0}$} \\
\hline SETORES & №. DE PESSOAS \\
\hline Agropecuária, extração vegetal e pesca & 1.274 \\
\hline Industrial & 1.189 \\
\hline Comércio de Mercadorias & 592 \\
\hline Serviços & 1.751 \\
\hline TOTAL & $\mathbf{4 . 8 0 6}$ \\
\hline \multicolumn{2}{|c|}{ Fonte: Fundação Instituto de Geografia e Estatística - IBGE } \\
\hline
\end{tabular}

\section{Serviços}

Saúde: 1hospital(is) - 41 leito(s)

Fonte: SUS - Ministério da Saúde, 2001.

Hotéis: 6

Fonte: Associação Brasileira de Indústria de Hotéis - ABIH, 2000.

\section{Água e Esgoto}

Concessionária Água: Prefeitura Municipal

Concessionária Esgoto: Prefeitura Municipal

Fonte: Companhia de Saneamento de Minas Gerais, 2002. 


\section{4 - Itanhandu}

Seu principal produto mineral, a bauxita, o coloca em 4이 lugar na produção mineira. Na indústria destaque para produção de calçados, doce de leite, laticínios, produtos químicos e farmacêuticos, 4 máquinas agrícolas, fécularia e móveis. 94\% da população é alfabetizada. Com isso, o município está em 2o lugar no País, com número menor de analfabetos. De Belo Horizonte dista 426 quilômetros, de São Paulo, 252 e do Rio de Janeiro 245. Passa Quatro e Verde são os rios que circundam a cidade.

O município originou-se de um pequeno arraial denominado Barra do Rio Verde. Graças às doações feitas por Joaquim de Almeida Campos, foi construída a primeira capela, dedicada a Nossa Senhora da Conceição. A imagem da santa padroeira da matriz de Itanhandu é a mesma que Joaquim de Almeida Campos doou à antiga capela. Em 1882, foi iniciada a construção da ferrovia no arraial de Barra do Rio Verde. A estação, inaugurada dois anos mais tarde, denominou-se Capivari. Em 1911, o local foi elevado a distrito, pertencente a Pouso Alto. E, em 1923, criou-se o município de Itanhandu, que quer dizer, em linguagem tupi-guarani, "pedra da ema".

A cultura na cidade tem seu ponto alto no Festival de Música de Itanhandu. Realizado tradicionalmente em julho, conta com a participação de cantores de Minas, Rio de Janeiro e São Paulo. Entre os atrativos naturais, encontra-se, a $20 \mathrm{~km}$ da cidade, a nascente do rio Verde, no alto da serra da Mantiqueira, com matas virgens, clima puro e belas paisagens.

Fonte: Secretaria da Cultura de Minas Gerais - 1999 


\begin{tabular}{|l|c|}
\hline \multicolumn{2}{|c|}{ População Ocupada por Setores Econômicos } \\
\hline \multicolumn{2}{|c|}{$\mathbf{2 0 0 0}$} \\
\hline SETORES & №. DE PESSOAS \\
\hline Agropecuária, extração vegetal e pesca & 1.039 \\
\hline Industrial & 1.766 \\
\hline Comércio de Mercadorias & 854 \\
\hline Serviços & 2.177 \\
\hline TOTAL & $\mathbf{5 . 8 3 6}$ \\
\hline \multicolumn{2}{|c|}{ Fonte: Fundação Instituto de Geografia e Estatística - IBGE } \\
\hline
\end{tabular}

\section{Serviços}

\section{Saúde:}

1hospital(is) - 62 leito(s)

Fonte: SUS - Ministério da Saúde, 2001.

Hotéis: 2

Fonte: Associação Brasileira de Indústria de Hotéis - ABIH, 2000.

\section{Água e Esgoto}

Concessionária Água: Prefeitura Municipal

Concessionária Esgoto: Prefeitura Municipal

Fonte: Companhia de Saneamento de Minas Gerais, 2002.

\section{5 - Passa Quatro}

Quando em 1937, descobriu-se a característica medicinal de suas nove fontes hidrominerais o lugar já lera grande produtor de cereais e tinha uma bem cuidada cultura de fumo já exportando, em 1925, cigarros manufaturados. Hoje, contando com excelentes fontes termais. O povoado nasceu em 1673, com a 
Bandeira de Félix Jacques. Quando, no séc. XVII, os bandeirantes Félix Jacques e Fernão Dias chegaram às terras da Mantiqueira, a garganta do Embaú Ihes deu passagem para a vertente oposta e eles descobriram, então, uma área cortada por um rio em várias direções. Neste local surgiram as primeiras casas e o povoado assim formado, por volta de 1773, recebeu o nome de Passa Quatro devido às quatro travessias feitas no rio pelos bandeirantes. Em 1854, é elevada a distrito e, em 1868, a freguesia. De freguesia passa a vila, tendo seu território desmembrado de Pouso Alto, em 1888.

Passa Quatro foi declarada estância hidromineral, em 1946. Ao lado da qualidade de sua água, oferece inúmeros atrativos, como o Campo do Muro, uma misteriosa muralha nos contrafortes da Mantiqueira; a gruta das Andorinhas, uma seqüência de corredeiras, cascatas e grutas escavadas na rocha; o Quilombo, uma série de cachoeiras próximo às ruínas de quilombos dos séc. XVII e XVIII, ou o túnel da Mantiqueira, inaugurado por Pedro II, o pico do Itaguaré, um dos mais altos do Brasil, a Floresta Nacional do Pinho, a serra do Cantagalo e a toca do Lobo. É de se destacar, também, a produção artesanal de vinho pela colônia italiana e a temporada de pesca às trutas, quando diversos criatórios soltam milhões de peixes que, pescados, podem ser preparados in loco.

Fonte: Secretaria da Cultura de Minas Gerais - 1999

\begin{tabular}{|l|c|}
\hline \multicolumn{2}{|c|}{ População Ocupada por Setores Econômicos } \\
\hline \multicolumn{2}{|c|}{$\mathbf{2 0 0 0}$} \\
\hline SETORES & №. DE PESSOAS \\
\hline Agropecuária, extração vegetal e pesca & 1.101 \\
\hline Industrial & 1.789 \\
\hline Comércio de Mercadorias & 786 \\
\hline Serviços & 2.505 \\
\hline TOTAL & $\mathbf{6 . 1 8 1}$ \\
\hline \multicolumn{2}{|c|}{ Fonte: Fundação Instituto de Geografia e Estatística - IBGE } \\
\hline
\end{tabular}




\section{Serviços}

Saúde:

1 hospital(is) - 62 leito(s)

Fonte: SUS - Ministério da Saúde, 2001.

Hotéis: 13

Fonte: Associação Brasileira de Indústria de Hotéis - ABIH, 2000.

\section{Água e Esgoto}

Concessionária Água: Prefeitura Municipal

Concessionária Esgoto: Prefeitura Municipal

Fonte: Companhia de Saneamento de Minas Gerais, 2002.

\section{6 - Pouso Alto}

No caminho natural para se cruzar a serra da Mantiqueira, os bandeirantes encontraram uma aldeia indígena e, nesta região, construíram um rancho no topo de uma elevação, exatamente onde hoje está a igreja matriz da cidade de Pouso Alto. O povoado passa, em 1748, a Freguesia de Nossa Senhora da Conceição de Pouso Alto. Em 1763, o proprietário da fazenda de Pouso Alto, Brás Esteves Leme, permite a construção de uma igreja nova junto ao terreiro da Casa Grande. Posteriormente, com a edificação de novas moradias, o povoado prosperou e, em 1874 cria-se o município, emancipandose de Baependi.

Fonte: Secretaria da Cultura de Minas Gerais - 1999 


\begin{tabular}{|l|c|}
\hline \multicolumn{2}{|c|}{ População Ocupada por Setores Econômicos } \\
\hline \multicolumn{2}{|c|}{$\mathbf{2 0 0 0}$} \\
\hline SETORES & No. DE PESSOAS \\
\hline Agropecuária, extração vegetal e pesca & 1.027 \\
\hline Industrial & 418 \\
\hline Comércio de Mercadorias & 367 \\
\hline Serviços & 774 \\
\hline TOTAL & $\mathbf{2 . 5 8 6}$ \\
\hline \multicolumn{2}{|c|}{ Fonte: Fundação Instituto de Geografia e Estatística - IBGE } \\
\hline
\end{tabular}

\section{Serviços}

\section{Saúde:}

1hospital(is) -28 leito(s)

Fonte: SUS - Ministério da Saúde, 2001.

Hotéis: 4

Fonte: Associação Brasileira de Indústria de Hotéis - ABIH, 2000.

\section{Água e Esgoto}

Concessionária Água: Prefeitura Municipal

Concessionária Esgoto: Prefeitura Municipal

Fonte: Companhia de Saneamento de Minas Gerais, 2002.

\section{7 - São Sebastião do Rio verde}

O núcleo que deu origem ao município foi formado nas proximidades da antiga estação da Rede Mineira de Viação e se desenvolveu a partir da construção da capela, em 1891. O distrito foi criado em 1953, com sede no povoado denominado Estação de Pouso Alto. Nove anos depois, São 
Sebastião do Rio Verde emancipa-se, com seu território desmembrado de Pouso Alto.

O município apresenta como atrativo natural o rio Verde, situado na área urbana, propício a canoagem e pescaria, possuindo, também, pequenas praias que possibilitam a natação

Fonte: Secretaria da Cultura de Minas Gerais - 1999

\begin{tabular}{|c|c|}
\hline \multicolumn{2}{|c|}{ População Ocupada por Setores Econômicos } \\
\hline \multicolumn{2}{|c|}{2000} \\
\hline SETORES & №. DE PESSOAS \\
\hline Agropecuária, extração vegetal e pesca & 237 \\
\hline Industrial & 90 \\
\hline Comércio de Mercadorias & 53 \\
\hline Serviços & 261 \\
\hline TOTAL & 641 \\
\hline
\end{tabular}

\section{Serviços}

Hotéis: Nenhum hotel.

Fonte: Associação Brasileira de Indústria de Hotéis - ABIH, 2000.

\section{Água e Esgoto}

Concessionária Água: Prefeitura Municipal

Concessionária Esgoto: Prefeitura Municipal

Fonte: Companhia de Saneamento de Minas Gerais, 2002. 


\section{8 - Virginia}

Portugueses foram os primeiros desbravadores da região, à procura de ouro e pedras preciosas. Como esse objetivo foi frustrado dedicaram-se à agricultura. Hoje, com mais de cem anos de existência, além da lavoura de subsistência, o município se sobressai no cultivo de frutas, sendo o primeiro produtor de marmelo e pêssego, o segundo de figo e o terceiro de pêra, do Estado.

As origens do município estão ligadas ao Ciclo do Ouro, quando desbravadores portugueses, não encontrando, no local, ouro ou pedras preciosas, resolveram fixar-se na região. Na metade do sec. XIX foi erguida uma capela dedicada a Nossa Senhora da Conceição, e o povoado que logo se desenvolveu ao seu redor recebeu o nome de Virgínia, em homenagem a Virgem Imaculada, padroeira do local. Com o tempo, o nome foi se modificando para Virgínia, sendo elevada a distrito em 1865, passando à categoria de município e separando-se de Pouso Alto, em 1911. Virgínia realiza em agosto ou setembro a sua exposição agropecuária, com torneio leiteiro, mostras do artesanato da região, desfiles de cavaleiros e shows de violeiros.

Fonte: Secretaria da Cultura de Minas Gerais - 1999

\begin{tabular}{|l|c|}
\hline \multicolumn{2}{|c|}{ População Ocupada por Setores Econômicos } \\
\hline \multicolumn{2}{|c|}{ SE00 } \\
\hline Agropecuária, extração vegetal e pesca & NNo. DE PESSOAS \\
\hline Industrial & 1.616 \\
\hline Comércio de Mercadorias & 454 \\
\hline Serviços & 189 \\
\hline TOTAL & 928 \\
\hline \multicolumn{2}{|c|}{ Fonte: Fundação Instituto de Geografia e Estatística - IBGE } \\
\hline
\end{tabular}




\section{Serviços}

\section{Saúde:}

1 hospital(is) 32 leito(s)

Fonte: SUS - Ministério da Saúde, 2001.

Hotéis: 1

Fonte: Associação Brasileira de Indústria de Hotéis - ABIH, 2000.

\section{Água e Esgoto}

Concessionária Água: Prefeitura Municipal

Concessionária Esgoto: Prefeitura Municipal

Fonte: Companhia de Saneamento de Minas Gerais, 2002.

\section{9 - Marmelópolis}

O município está situado no extremo da região sul, em pleno maciço da Mantiqueira e é banhado pelo rio Santo Antônio, que se constituía numa das vias de acesso utilizadas pelas bandeiras que penetravam o território de Minas Gerais, no auge do Ciclo do Ouro. Em torno das lavras de Moniz Pinto Coelho da Cunha, surge o Arraial no terreno doado por Antônio Garcia Velho e elevado à freguesia de Nossa Senhora da Soledade de Itajubá em 1757. A freguesia de Nossa Senhora da Soledade de Itajubá transformou-se no município de Delfim Moreira, cujo povoado de Queimada é elevado à categoria de distrito em 1953, originando o município de Marmelópolis em 1962. Segundo declaração do prefeito Francisco Ribeiro da Mata em 1967, a denominação atual deve-se ao fato de ser ele um dos maiores produtores de marmelo do mundo. 
Fonte: Secretaria da Cultura de Minas Gerais - 1999

\begin{tabular}{|l|c|}
\hline \multicolumn{2}{|c|}{ População Ocupada por Setores Econômicos } \\
\hline \multicolumn{2}{|c|}{$\mathbf{2 0 0 0}$} \\
\hline SETORES & №. DE PESSOAS \\
\hline Agropecuária, extração vegetal e pesca & 639 \\
\hline Industrial & 153 \\
\hline Comércio de Mercadorias & 113 \\
\hline Serviços & 240 \\
\hline TOTAL & $\mathbf{1 . 1 4 5}$ \\
\hline \multicolumn{2}{|c|}{ Fonte: Fundação Instituto de Geografia e Estatística - IBGE } \\
\hline
\end{tabular}

Serviços

Hotéis: Nenhum hotel

Fonte: Associação Brasileira de Indústria de Hotéis - ABIH, 2000.

\section{Água e Esgoto}

Concessionária Água: Prefeitura Municipal

Concessionária Esgoto: Prefeitura Municipal

Fonte: Companhia de Saneamento de Minas Gerais, 2002. 


\section{UM PÓLO DE ECOTURISMO QUASE VIRTUAL}

A região possui muitos atrativos naturais e culturais. Não somente pelo simples fato de estar localizado nos arredores da serra da Mantiqueira e ter sido caminho de bandeirantes, mas também pelo povo tão acolhedor e simpático que vive na região. Infelizmente o que vemos hoje, não é um circuito estruturado para receber visitantes.

É impossível um turista conhecer o Pico dos Marins e se hospedar em um hotel em Marmelópolis, pois a cidade não possui hotéis preparados para receber turistas. Não possui guias preparados para levar os visitantes em um dos passeios mais bonitos do país. Falta infra-estrutura básica para a própria população. Este é um dos muitos exemplos de realidade que vimos hoje nas cidades deste pólo. Se o local não é bom para a população, como vai ser bom para o turista?

O circuito Terras Altas teve início em 1998 através de um plano diretor turístico da micro-região. $O$ trabalho foi contratado pelo Governo de Minas Gerias com a empresa Plano e Mensagem e dirigido pelo Professor Ernesto Guilhenea Melgar. A partir de um simples levantamento de informações básicas sobre os municípios foram elaboradas diretrizes para 0 desenvolvimento do turismo. Mas onde está o inventário? O diagnóstico? $\mathrm{O}$ envolvimento da sociedade? A valorização da cultura? Um simples levantamento de dados pode analisar problemas e oportunidades?

Este documento foi organizado em três partes, sendo a primeira um levantamento de informações básicas sobre cada município que integra o circuito. Análise dos objetivos municipais relacionados com a atividade turística, inventário de recursos (que na verdade foi um simples levantamento), mercados atuais e potenciais, acessos e infra-estruturas, análise dos pontos fortes e fracos para o desenvolvimento desta atividade. A segunda parte contempla a metodologia e os princípios que orientam a estratégia do plano e os custos benefícios dos impactos sociais econômicos e ambientais. $\mathrm{Na}$ 
terceira parte é exposta a estratégia geral para o Turismo. São apresentadas as conclusões para formar as diretrizes estratégicas ao nível da micro-região das "Terras Altas da Mantiqueira".

Depois de elaborado, o plano foi apresentado aos prefeitos das cidades que faziam parte deste circuito e que por sua vez constituíram a ATAM Associação das Terras Altas da Mantiqueira. $O$ principal objetivo desta associação, de acordo com o Estatuto consolidado da sociedade civil denominado Terras Altas da Mantiqueira é (anexo 1):

".a promoção da imagem da Região, denominada Terras Altas da Mantiqueira, criada conforme resolução 001/98 dos Srs. Prefeitos das cidades de Alagoa, Delfim Moreira, Itamonte, Itanhandu, Marmelópolis, Passa Quatro, Pouso Alto, São Sebastião do Rio verde, Virgínia, todas situadas no sul do Estado de Minas Gerais, bem como a integração das empresas situadas nestes municípios, visando incrementar a indústria turística da região e atividades correlatas, bem como a expansão da cultura regional, proteção e preservação do meio ambiente."

Através de uma grande campanha de marketing, o circuito começou a ser divulgado através de sites, folderes e cartazes produzidos pela TURMINAS e espalhados por todo o estado de Minas Gerais.A promoção realmente foi feita de acordo com o estatuto, mas e o resto? A região se tornou praticamente um pólo de ecoturismo virtual. Existe o atrativo, mas como chegaremos nele? Empresários da região deslumbrados com a possibilidade de ficarem ricos da noite para o dia com o grande número de turistas que viriam para a região investiram em boates, bares e outros empreendimentos para receber estes valiosos visitantes. Mas nada de disso aconteceu conforme visto na entrevista realizada com o Sr. Eduardo (anexo 3). Os visitantes vieram e ao se depararem com a falta de infra-estrutura do local, não permaneceram nas localidades integrantes do circuito. Como ficar em Itanhandu para tomar banho em poços de água limpa, se as margens do rio estão cheias de esterco de galinha que 
vêm das inúmeras granjas da cidade, prejudicando a água e conseqüentemente toda a população do local?

Em Delfim Moreira é possível se hospedar em uma belíssima pousada no centro da cidade, conhecer os inúmeros pesqueiros de trutas que se encontram em seus arredores e até fazer trilhas na serra da Mantiqueira. Segundo a coordenadora do Sebrae do Sul de Minas, Jussara, foi feito um grande trabalho para o desenvolvimento do turismo em Delfim Moreira. Uma jornada técnica foi realizada com moradores e empreendedores interessados ou integrados no desenvolvimento do turismo (conforme anexo 4). Aspectos positivos e negativos foram levantados mas o plano de desenvolvimento do turismo não saiu. Não existe um plano de ações para o turismo, segundo depoimento do secretário de turismo de Delfim Moreira (anexo 2). Os grandes investimentos feitos na cidade na gestão passada não estão trazendo lucros ou divisas para a cidade, pois o novo prefeito abandonou o projeto. Delfim Moreira foi uma das últimas cidades a fazer parte do circuito e já possuía um plano de turismo próprio para o local. Ao fazer parte da ATAM a prefeitura deixou o projeto que estava em desenvolvimento de lado para dar início ao circuito, que como podemos notar não saiu do papel. Nenhuma ação foi tomada para a continuidade do projeto.

Hoje Delfim Moreira recebe o mesmo número de turistas que recebia antes das Terras Altas. O circuito não trouxe nenhum benefício à população local. A cidade poderia estar recebendo um grande número de visitantes. Boa vontade da população não falta, mas vontade política pode ser um grande empecilho para o desenvolvimento desta atividade.

Políticos se aproveitaram desse novo negócio para fazerem suas campanhas políticas e alguns até se elegerem em cargos das prefeituras municipais. Participação em feiras e eventos turísticos também foi oferecido pelo governo do estado, para a divulgação do pólo. Apenas um evento foi realizado nesta gestão: $O 1^{\circ}$. Festival de queijo das Terras Altas da Mantiqueira 
em 21 e 22 de julho de 2002. Este projeto foi uma iniciativa do Hotel São Gotardo localizado em Itamonte.

Na verdade o que se vê hoje é a tentativa de reconquistar a confiança da população local e agora começar a trabalhar com os princípios básicos do ecoturismo que estão contidos na sua definição adotada neste trabalho: o desenvolvimento sustentável, formação de uma consciência ambientalista, bem estar das populações envolvidas. Podemos notar este interesse de mudanças no Projeto Político Administrativo da ATAM para 2002-2003 (vide anexo 5):

“.A gestão 2002-2003 tem como objetivo principal reconquistar a confiança da sociedade civil, do empresariado local e da classe política regional para esta Associação para que possamos, juntos, promover o desenvolvimento do "Circuito Turístico Terras Altas da Mantiqueira". Acreditamos que, sem o envolvimento de todos não conseguiremos o que nós da atual diretoria da Associação Terras Altas da Mantiqueira, consideramos o objetivo principal da entidade: o desenvolvimento do Turismo como alternativa de desenvolvimento econômico regional..."

Através de parcerias com empresas públicas e privadas para capacitação, conscientização e envolvimento da população este grande projeto poderá ser reformulado e ter um grande reinício. É necessário sim reconquistar a confiança da população e chamá-la para fazer parte deste trabalho. 0 turismo e o ecoturismo podem ser uma ótima alternativa para 0 desenvolvimento desta região. 


\section{CONCLUSÃO}

O Turismo envolve mais de 52 setores da economia na sua cadeia produtiva. Todos ganham quando seu planejamento é feito de forma participativa visando o benefício de todos envolvidos. Para que se aja um plano bem elaborado em princípio, é necessário o conhecimento do local ou região que se quer trabalhar. Levantar os principais atrativos potenciais e já existentes juntamente com a população são primordiais. Análise do ambiente externo e interno, diagnóstico e só então formatar metas, objetivos e projetos é um dos métodos adotados por planejadores de turismo. Independente do método usado para se fazer um plano, uma coisa não pode faltar de maneira alguma em nenhum projeto de turismo ou ecoturismo: a participação da comunidade. Se a comunidade não quiser, nada acontece.

O circuito Terras Altas da Mantiqueira pecou justamente neste ponto, quis colocar o circuito na mídia sem antes estar preparado. O pólo existe, somente nos sites, folderes e propagandas que foram feitas. Pico dos Marins é divulgado como um atrativo, mas como os turistas conseguirão atingir seu topo? Não existe estrutura para isso. Sem preparo da comunidade, infraestrutura básica e turística, segurança, opções para diversos tipos de turistas e políticas que realmente se interessem pelo crescimento local, o local não consegue se firmar como um destino. Hoje este pólo começa a se reerguer. Potencial não falta. Falta uma visão diferenciada por parte dos integrantes da ATAM em prol da região e não somente em benefício próprio.

Inventários estão sendo elaborados por algumas cidades em parcerias com faculdades de turismo da região. Novas reuniões programadas, procura de parcerias, formatação de produtos ecoturísticos, a valorização e melhoria de produtos locais e regionais, podem ser a solução ou o princípio dela para que as atividades caminhem de forma ordenada e participativa. Apesar de todos os problemas enfrentados não se pode desperdiçar um grande potencial para 0 desenvolvimento do ecoturismo. É com erros e acertos que o turismo caminha hoje no Brasil. Devemos lutar para que menos erros e mais acertos sejam 
feitos nesta área.Terras Altas da Mantiqueira começou, ou quis começar com muito mais erros do que acertos. Já não está na hora de começarem a acertar? 


\section{BIBLIOGRAFIA}

Diretrizes para uma política nacional de ecoturismo / Coordenação de Silvio Magalhães Barros II e Denise Hamú M. de La Penha. Brasília: EMBRATUR, 1994.

Ecoturismo: um guia para planejamento e gestão / Kreg Lindberg, Donald E. Hawkins (editores); prefácio de David Western; tradução de Leila Cristina de M. Darin; revisão técnica de Oliver Hillel, $2^{\text {a }}$ edição.- São Paulo: Editora SENAC São Paulo, 1999.

ECOTURISMO: visitar para conservar e desenvolver a Amazônia/ Texto elaborado por: Luiz Fernando Ferreira, Maria do Carmo Barêa Coutinho. Brasília: MMA/SCA/PROECOTUR, 2002.52p.

IGNARRA, Luiz Renato. Fundamentos do Turismo. São Paulo/SP. Editora Pioneira, 1999.

BARRETO, Margarita. Manual de Iniciação ao Estudo do Turismo. 2ª . Edição. Campinas/SP. Editora Papirus, 1997.

PETROCCHI, Mário. Gestão de pólos turísticos. São Paulo: Futura, 2001.

MAGALHÃES, Guilherme Wendel de - coordenador. Pólos de Ecoturismo: Planejamento e Gestão. 1를 edição - São Paulo: TERRAGRAPH, 2001.

Endereço eletrônico : www.polosdeecoturismo.com.br consulta feita em 24 de fevereiro de 2003.

Endereço eletrônico : www.descubraminas.com.br consulta feita em 25 de fevereiro de 2003.

Endereço eletrônico : http://www.mg.gov.br/ consulta feita em abril de 2003. 
Endereço eletrônico : http://www.bussolanet.com.br/turismo/ consulta feita em abril de 2003.

Endereço eletrônico: http://www.turismo.mg.gov.br/circuit.htm consulta feita em maio de 2003. 
10. ANEXOS 
ANEXO1 - Estatuto Consolidado da sociedade civil denominada Terras Altas da Mantiqueira 
Anexo 2 - Entrevista realizada com o secretário de turismo de Delfim Moreira.

1) QUAL O NOME COMPLETO DO SR? QUAL A SUA FORMAÇÃO?

Marcelo Aparecido Braga. Formado em direito pela faculdade de Direito do sul de Minas e atualmente estou fazendo o curso de biologia.

2) A QUANTO TEMPO EXISTE A SECRETARIA DE TURISMO EM DELFIM MOREIRA?

A secretaria de Turismo foi criada em 1997 e funcionou até 2000. De 2001 a 2003 ninguém assumiu o cargo e somente agora é que estamos retornando às atividades.

3) EXISTE UM PLANO PARA O DESENVOLVIMENTO DO TURISMO EM DELFIM?

Não. O plano que estamos querendo desenvolver atualmente é de recadastrar as empresas que trabalham na área de turismo para poder melhorar nosso site de divulgação da cidade.

4) EXISTE ALGUM PROGRAMA SENDO DESENVOLVIDO NA ÁREA DE TURISMO?

Não existe.

5) SE SIM. ESTE PLANO FOI FEITO DE FORMA PARTICIPATIVA?

6) O QUE O TURISMO SIGNIFICA PARA O SEU MUNICÍPIO?

Uma alternativa de renda para a população.

7) QUANTOS TURISTAS VOCÊS RECEBEM POR MÊS/ANO?

Não temos nenhum dado ou pesquisa realizada nesta área de turismo. Os próprios empreendedores é que fazem suas pesquisas.

8) O QUE SIGNIFICA FAZER PARTE DO CIRCUITO TERRAS ALTAS DA MANTIQUEIRA?

Agora é que nós estamos voltando a participar das reuniões das Terras Altas, pois como não havia secretaria de turismo, não havia participação. Sei que era cobrada uma taxa mensal ou semestral, mas a prefeitura também não pagou.

9) COM A ENTRADA DO MUNICÍPIO NESTE PÓLO, A FREQUÊNCIA DOS TURISTAS QUE VEM AO MUNICÍPIO AUMENTOU? EM QUANTOS POR CENTO? 
Eu acho que aumentou um pouco, mas não pelas Terras Altas, mas pelos novos empreendimentos daqui da região. Os pesqueiros são os principais atrativos que temos aqui. Existem outros atrativos que não são divulgados nos sites de turismo como, por exemplo: grutas e cachoeiras, pontilhões, parte histórica, cachoeira do túnel, estação férrea, etc. Temos muito problema com o patrimônio histórico porque nada é tombado aqui na cidade. Os moradores têm medo do tombamento porque depois que for efetivado não poderão mais mexer em suas casas. Existem construções muito antigas e importantes aqui na cidade.

\section{0)QUAIS OS ATRATIVOS MAIS PROCURADOS NA CIDADE?}

Os pesqueiros e as trilhas na serra.

\section{1)COMO É FEITA A DIVULGAÇÃO DO MUNICÍPIO?}

Apenas através do site de Delfim Moreira.

\section{2)COMO É FEITA A GESTÃO DA ASSOCIAÇÃO TERRAS ALTAS DA MANTIQUEIRA?}

Não tenho informação sobre isso. Não possuo nem o estatuto.

\section{3)QUAIS OS BENEFÍCIOS GERADOS POR ESTA ASSOCIAÇÃO?}

Para nós aqui por enquanto nenhum, acho que somente a divulgação.

\section{4)EXISTE ALGUM PROGRAMA DE GERAÇÃO DE TRABALHO DE RENDA NO MUNICÍPIO? QUAIS?}

Foram realizados alguns cursos pelo FAT (fundo de amparo ao trabalhador) como garçom, recepcionista. Mais ligado a esse tipo de mão-de-obra. $O$ sebrae, na gestão passada fez um trabalho muito bom aqui na cidade. Desenvolveu muitas oficinas para as pessoas que trabalhavam ou tinham algum interesse pelo turismo. Foi uma jornada técnica, levantando os principais problemas do município. Mas o prefeito não deu continuidade ao projeto e quando a cidade entrou para as "Terras Altas" o sebrae parou com os trabalhos no município.

15)DELFIM MOREIRA POSSUI UMA ESCOLA TÉCNICA (FUNDAÇÃO ROGÊ) QUE OFERECE O CURSO DE TURISMO RURAL, VOCÊS TEM ALGUMA PARCERIA COM ESSA ESCOLA?

Não temos porque o dono da escola é o ex-prefeito de Delfim Moreira que perdeu a reeleição. Por essa rixa que existe entre o atual prefeito e o diretor da escola técnica não conseguimos firmar nenhuma parceria com eles.

16)A PREFEITURA INVESTE NOS ATRATIVOS TURÍSTICOS DO LOCAL? 
Não existe nenhum investimento. Os próprios donos dos atrativos (quando tem dono) é que investem no local. Pra você ter uma idéia não existe nem rodoviária no município. $\mathrm{O}$ ônibus chega e deixa os passageiros na praça em frente a Matriz e para sair é a mesma coisa.

\section{7)EXISTE ALGUM INCENTIVO FISCAL PARA EMPRESAS} TURÍSTISCAS SE INSTALAREM NO LOCAL?

Não existe nenhum incentivo porque a lei de responsabilidade fiscal nos prejudica muito. Para uma empresa receber esse tipo de benefício tem que haver uma contrapartida fiscal ou financeira também, o que acaba complicando bastante.

\section{8)E O ARTESANATO? EXISTE ALGUM PROJETO PARA A VALORIZAÇÃO OU COMERCIALIZAÇÃO DO MESMO?}

Existe uma associação dos artesãos de Delfim Moreira a ADART, mas não existe nenhuma sede da mesma. Falta vontade política. Quando tem alguém na associação que não "bate" com o prefeito as coisas complicam. Todo ano é realizada uma exposição agropecuária aqui em Delfim e os artesãos tem seu espaço garantido. Não é cobrada nenhuma taxa da associação.

\section{9)O QUE VOCÊS ESTÃO FAZENDO NO MOMENTO PARA O TURISMO AQUI EM DELFIM MOREIRA?}

Vai ser realizada a exposição agropecuária este mês, que é um grande evento aqui de Delfim. Recentemente compramos o antigo prédio onde funcionava a fábrica da CICA por $\mathrm{R} \$ 140.000,00$. A área possui 2,82 hectares de área que pretendemos utilizar para realização de eventos. Inclusive a exposição vai ser realizado lá este ano. 
ANEXO 3 - Entrevista realizada com o Sr Eduardo, proprietário de uma Pousada e um Restaurante em Delfim Moreira.

NOME

Eduardo (Português)

1) ATIVIDADE RELACIONADA AO TURISMO?

Dono da Pousada Solar da Mantiqueira e do Restaurante Canto do Caipira.

\section{2) QUANTOS TURISTAS O SR RECEBE POR MÊS?}

Não sei, mas já que não temos a colaboração da prefeitura, acho que recebemos um número razoável.

3) APÓS A ENTRADA DA CIDADE NO CIRCUITO TERRAS ALTAS (1998), O NÚMERO DE TURISTAS AUMENTOU?

Não, porque não houve integração da cidade de Delfim Moreira com as outras cidades do circuito. As estradas de acesso são precárias. Muitas pessoas daqui não sabem nem chegar as outras cidades do circuito. Faltou um marketing global do circuito.

4) QUAIS ATRATIVOS SÃO MAIS PROCURADOS PELOS TURISTAS?

Natureza, montanhas, rios e cachoeiras.

5) QUAL A MAIOR RECLAMAÇÃO DOS TURISTAS?

Não existem muitas reclamações porque nunca fiz nenhuma pesquisa. O que eu ouço aqui é reclamação sobre as estradas, os celulares não pegam, sinalização turística precária e a falta de ajuda governamental por se tratar de um lugar tão belo.

6) O QUE VC ACHA QUE DEVE MUDAR? PORQUE?

A consciência das pessoas da localidade. Muitas não sabem os benefícios que o turismo pode trazer para cá. Sou da llha da Madeira e sempre convivi com o turismo, falta muita experiência por parte das pessoas que estão trabalhando aqui hoje.

7) O SENHOR FEZ ALGUM CURSO DE CAPACITAÇÃO NA ÁREA EM QUE TRABALHA?

Tudo o que aprendi foi com minha vivência.

8) QUAL FOI SEU INVESTIMENTO NA POUSADA E NO RESTAURANTE? 
Meu investimento foi de aproximadamente $R \$ 500.000,00$, mas sei que para ter esse retorno vai demorar bastante.

\section{9) COMO É FEITA A DIVULGAÇÃO DE SEU ESTABELECIMENTO?}

Divulgamos através do site, revistas de turismo, caderno de turismo de grandes jornais, rádios, televisão, folderes. A maior divulgação é feita em São Paulo, Rio de Janeiro e Belo Horizonte pois sei que é um grande mercado a ser atingido. Os turistas já chegam com informações de atrativo que querem conhecer. No site inclui vários atrativos da região e bastante coisa sobre a cidade.

\section{0) O SENHOR ESTÁ SATISFEITO COM A PARTICIPAÇÃO DA CIDADE NESTE CIRCUITO?}

Pra mim não fez diferença, estou caminhando com minhas próprias pernas.

11) COMO O SENHOR TEM VISTO A PARTCIPAÇÃO DA SECRETARIA DE TURISMO NO DESENVOLVIMENTO DO TURISMO EM DELFIM.

Para o prefeito, só interessa o lucro. O secretário de Turismo é um amigo dele e antigo vereador daqui. Ele nunca trabalhou nesta área. Não existe um plano de desenvolvimento do turismo aqui. O prefeito anterior a este conseguiu desligar Delfim Moreira do sebrae da região. Não sei o que fizeram, mas havia um trabalho muito bom aqui que foi jogado fora.

12) O SENHOR OFERECE PASSEIOS PARA OS TURISTAS? UTILIZA GUIAS LOCAIS?

Sim. Ofereço muitos passeios e todo final de semana organizo grupos e contrato guias para leva-los.

13) O SENHOR TRABALHA COM OS ALUNOS DA ESCOLA TÉCNICA?

Não. Foi realizado um curso de guia pela escola e quando chamei os alunos para levarem um grupos, os mesmos não sabiam onde ficava o atrativo.

14) O SENHOR UTILIZA MÃO DE OBRA LOCAL PARA TRABALHAR NO RESTAURANTE E NA POUSADA?

Sim. Os funcionários foram treinados pela minha esposa e fazem cursos de capacitação, quando são realizados. 
ANEXO 4 - Jornada Técnica realizada pelo Sebrae na cidade de Delfim Moreira em 1999. 


\section{ANEXO 5}

\section{Projeto Político Administrativo \\ Associação Terras Altas da Mantiqueira: Biênio 2002 - 2003}

\section{Introducão:}

A gestão 2002-2003 tem como objetivo principal reconquistar a confiança da sociedade civil, do empresariado local e da classe política regional para esta Associação para que possamos, juntos, promover o desenvolvimento do "Circuito Turístico Terras Altas da Mantiqueira".

Acreditamos que, sem o envolvimento de todos não conseguiremos o que nós da atual diretoria da Associação Terras Altas da Mantiqueira, consideramos o objetivo principal da entidade: o desenvolvimento do Turismo como alternativa de desenvolvimento econômico regional.

Temos a intenção de tornar esta associação, uma entidade democrática, na qual seja possível a participação de todos.

A Industria do Turismo envolve mais de cinqüenta setores da economia brasileira: estão no topo da cadeia produtiva o setor de hospedagem (hotéis e pousadas), restauração (restaurantes, lanchonetes, etc), artesanatos e agências de turismo.

Para sustentar esses setores, é necessária toda uma infraestrutura de transporte, médica, farmacêutica, eventos, comércio em geral além de serviços diversos e outros tantos que produzem empregos diretos e indiretos beneficiando toda a população.

E é por acreditar na possibilidade de desenvolvimento econômico, criação de empregos, aquecimento do comércio local e do setor de prestação de serviços, que hoje doamos um pouco de nosso valioso tempo para podermos trabalhar em benefício da comunidade através do esforço persistente dentro desta instituição.

Portanto, temos plena convicção de que, produzindo um trabalho de qualidade, com envolvimento da comunidade, participação e aval de todos, inclusive de entidades pré-existentes, podemos em conjuntos promover o desenvolvimento econômico regional, com geração de emprego, aumento do 
poder aquisitivo da população e conseqüente melhoria na qualidade de vida de todos.

\section{Objetivo:}

Restaurar e tornar funcional a Associação Terras Altas da Mantiqueira, provendo-a de meios de obtenção de receita própria; realizar - levantamento do potencial turístico da região e sua transformação em produto, dentro de padrões de excelência.

\section{Desenvolvimento:}

1. Reestruturação funcional e física:

1.1. Revisão Estatuária.

1.2. Formação de rede de contribuição.

1.3. Sede.

2. Levantamento dos empreendimentos ligados direta ou indiretamente ao turismo, relacionando-os aos em torno de 56 setores econômicos brasileiros ligados de alguma maneira à cadeia produtiva do turismo.

3. Desenvolvimento da Infra-estrutura Turística:

3.1. Levantamento e diagnóstico dos atrativos, dividindo-os em potenciais, e de aproveitamento imediato; manejo diferenciado para essas duas vertentes..

\subsection{Estruturação.}

4. Educação:

4.1. Seminários sobre diversos setores do turismo.

4.2. Cursos técnicos profissionalizantes.

4.3. Atividades Extracurriculares.

4.4. Eventos de estudos turísticos.

4.5. Treinamento da comunidade em atendimento turístico, obedecendo padrões de excelência compatíveis com os grandes centros turísticos nacionais.

5. Promover o circuito:

5.1 Participação em feiras.

5.2 Confecção de Material de Propaganda e Marketing.

5.3 Participar da Promoção dos eventos regionais.

6. Celebração de Convênios Diversos (SEBRAE, SENAC, SENAI, faculdades de turismo, etc).

\section{Metodologia:}

? Estudar o plano diretor como guia para tomada de decisão. 
? Cadastramento dos interessados no desenvolvimento do turismo da região.

? Formação de grupo de trabalho com representantes de todos municípios.

? Realização de reuniões semanais itinerante com o grupo de trabalho.

? Dividir responsabilidade para somar resultados.

? Realização de Assembléias Mensais Itinerantes.

? Criação de um selo de identificação das pessoas físicas e jurídicas, públicas ou privadas que contribuem para o desenvolvimento da entidade.

ASSOCIAÇÃO TERRAS ALTAS DA MANTIQUEIRA

DIRETORIA - BIÊNIO 2002/2003

Richardson Resek Silva - Sandra Oestmann 